\title{
Water pollution prevention and state of the art treatment technologies
}

\author{
Chih-Huang Weng ${ }^{1}$ \\ Published online: 20 July 2020 \\ (C) Springer-Verlag GmbH Germany, part of Springer Nature 2020
}

This special issue (SI) of Environmental Science and Pollution Research (ESPR) includes a collection of 18 peer-reviewed articles relating to water quality and toxicity risk assessments, ecosystem protection, groundwater contamination assessment, soil and sediment remediation technologies, water treatment technologies, climate change adaptation and mitigation strategies, and control of carbon intensity that were formally presented at the 4th International Conference on Water Resources and Environment (WRE 2018), the 5th International Conference on Water Resources and Environment (WRE 2019), and the 1st International Conference on Advances in Civil and Ecological Engineering Research (ACEER 2019). WRE 2018 was held in I-Shou University, Kaohsiung, Taiwan, from July 17th to 21st, 2018. WRE 2019 was held in Macau University of Science and Technology, Macao, China, from June 16th to 19th, 2019. WRE conference started in 2015, when the first WRE was held in Beijing. As an annually held conference, the upcoming 6th WRE conference is prescheduled held in Tokyo, from 23rd to 26th, 2020; however, due to the outbreak of COVID-19 and for the safety of participants, WRE2020 will be held online via virtual presentation (http://www.wreconf.org/index.html). The WRE conference highlighted the needs to maintain the sustainability of indispensable water resources under increasing uncertainty and to protect the fragile water environments under the growing concern of intensive use of water we are facing today. While Civil Engineering provides us a better living environment, there is a need not only to protect our fragile environment but also to ensure it is sustainable for future generations. Thus, the initiation of ACEER 2019 is to emphasize links between civil engineering research and

Responsible editor: Philippe Garrigues

Chih-Huang Weng

chweng@isu.edu.tw

1 Department of Civil and Ecological Engineering, I-Shou University, Kaohsiung, Taiwan knowledge of ecological/environmental issues. The 2 nd ACEER will be held on October 20th-23rd, 2020, in Beijing, China (http://www.aceerconf.org/index.html). The present SI of ESPR was guest-edited by Professor Chih-Huang Weng (I-Shou University, Kaohsiung, Taiwan). The papers selected in this SI were based on the ones originally presented at the conference; however, having gone through the regular peerreview process of ESPR, the contents of those papers have been changed. A brief highlight of the papers included in this SI is as follows:

- Constantly consumption of caffeine around the world has led to increase in caffeine concentration in water bodies and agricultural soil, and thus the impact of caffeine on the environment should not be ignored. Korekar et al. (2019) review the caffeine occurrence, its persistence and remediation.

- Cui et al. (2019) compared the acute toxicity of five oil spill dispersants to three organisms at different trophic levels. They found dispersants with Fuken-2 and HLD-501 exhibiting no acute toxicity to all tested organisms.

- Miao et al. (2019) applied the remote sensing technique to develop models of Canadian Water Quality Index (CWQI) scores from satellite data to assess the water quality for two major urban rivers within the Linyi development area. Such advanced assessment approach is effectiveness and robustness and can indicate actual water quality patterns.

- Yeh et al. (2020) demonstrate that the synergistic heavy metal contamination degree of an industrially affected river and its adverse biological effects can be assessed by employing the heavy metal pollution index, the degree of contamination index, the contamination factor, the index of geo-accumulation, and hazard quotients. This assessment practice can be quite useful to provide a reference for establishing river pollution control and management strategies. 
- With the help of ionic tracers and employing the spiraling curve characterization approach and the MichaelisMenten equation, Song and Song (2019) revealed that the dynamic absorption characteristics of $\mathrm{NO}_{3}-\mathrm{N}$ in a rural-urban ecotone channel is slightly influenced by the hydrological factors, but significantly influenced by the geomorphic features of the channel.

- On the basis of a 23-year dataset of eleven cities in the Songhua River Basin, Wanhong et al. (2019) ultimately developed two econometric models to quantify the industrial wastewater discharge allowance and ecocompensation of the investigated cities, respectively. They suggested that the ecosystem can be protected via an emissions trading program, which permits the wastewater discharge allowance to trading market.

- Sekine et al. (2020) proposed a user-friendly procedure for estimating the performance of river fish habitat evaluation based on the comparison of width-to-depth ratio and ecoenvironmental diversity. This procedure is of particular applicability to small river construction works.

- Gao et al. (2019) highlights the anomalous As and $\mathrm{F}^{-}$ concentration in the phreatic and confined groundwater of Xi'an city, China, was not only attributed to the upward flow of geothermal water through faults and ground fissures but also related to the anthropogenic activities.

- Zhou et al. (2019) present a case study of using aquatic chemistry and isotopic composition of groundwater to trace groundwater circulation in the Xinchang preselected site (China) that has encountered geological disposal of high-level radioactive waste.

- Technologies of treating gray water (GW) as reclaimed water is now available. Based on a 1-year laboratory-scale experiment, Ren et al. (2019) claimed that GW treated by both membrane bioreactor (MBR) and biological aerated filter (BAF) all meet the criteria of water reuse for toilet flushing, but using GW purified by MBR is more viable for toilet flushing.

- Li et al. (2019) adopted a sequencing biofilm batch reactor (SBBR) to perform comparative study of four different carriers on ammonia and COD removal from the effluent of zero-discharge marine recirculating aquaculture system (MRAS). They concluded that the ceramsite-packed SBBR is feasible for MRAS wastewater treatment.

- Pang et al. (2019) synthesized a novel composite, titanium dioxide/activated carbon $\left(\mathrm{TiO}_{2} / \mathrm{AC}\right)$, where $\mathrm{AC}$ derived from oil palm empty fruit bunch, that could achieve a significantly degradation efficiency of organic dye under ultrasonic irradiation. The $\mathrm{TiO}_{2} / \mathrm{AC}$ composite remained effective in dye degradation even after second catalytic cycle, showing the possible future applicability to textile industry.

- The production of nanoparticles can be more environmental-friendly without the use of chemical compounds. Chan et al. (2019) present a green synthesizing route using Clitoria ternatea Linn aqueous extract as reducing and stabilizing agents for synthesizing the silverdoped zinc oxide (Ag-doped $\mathrm{ZnO}$ ) nanoparticles. The biosynthesized Ag-doped $\mathrm{ZnO}$ nanoparticles could significantly enhance its sonocatalytic activity over $\mathrm{ZnO}$ nanoparticles based on the test results of Congo red degradation efficiency.

- Le et al. (2019) revealed that progressive freezing is a costeffective technology for draw solute recovery in forward osmosis process. They also provided mass transfer coefficients depended on the ice front speed and the stirring rates for the needs of future scaling up experiments.

- Using magnetite-carbon black composites as a persulfate activator, Dong et al. (2019) revealed that such PS oxidation processes could effectively degrade polycyclic aromatic hydrocarbons (PAHs) in sediment at circumneutral $\mathrm{pH}$. They suggest that the cytotoxicity of the PAH degradation products assessed by the zebrafish (Danio rerio) embryonic cell line is more sensitive than human hepatoma carcinoma cell line.

- Peng et al. (2019) found that poly- $\gamma$-glutamic acid ( $\gamma$ PGA), an environmentally friendly washing reagent, is effective in removing heavy metals $(\mathrm{Cu}, \mathrm{Zn}, \mathrm{Ni}$, and $\mathrm{Cr}$ ) from metal-contaminated farmland soil. The efficacy of metal removal in the field pilot-scale tests is mainly governed by the order of $\gamma$-PGA concentration, washing time, liquid/soil ratio, and rotational speed.

- Lee and Lin (2019) provide relationships between integrated vulnerability (biophysical and social) and personal ecological footprint of Taipei (urban) and Yunlin county (rural), Taiwan, for governments and communities to establish implementation strategies in risk areas to adapt and mitigate to climate change.

- The carbon intensity of a country is closely related to its economic system. Based on a selection of 24 countries and application of endogenous growth model, Wang et al. (2020) revealed that countries with high or medium high income show convergence of carbon intensity; however, countries with medium or low income exhibit insignificant convergence tendency in carbon intensity.

\section{References}

Chan YY, Pang YL, Lim S, Lai CW, Abdullah AZ, Chong WC (2019) Biosynthesized $\mathrm{Fe}$ - and $\mathrm{Ag}$-doped $\mathrm{ZnO}$ nanoparticles using aqueous extract of Clitoria ternatea Linn for enhancement of sonocatalytic degradation of Congo red. Environ Sci Pollut Res. https://doi.org/ 10.1007/s11356-019-06583-Z

Cui Z, Luan X, Li D, Li Q, Shuai L, Zheng L, Sun C, Wang G (2019) Comparative toxicity of five dispersants to test organisms at different trophic levels: Platymonas helgolandica, Ruditapes 
philippinarum, and Acinetobactersp. Tox2. Environ Sci Pollut Res. https://doi.org/10.1007/s11356-019-04562-y

Dong CD, Tsai ML, Wang TH, Chang JH, Chen CW, Huang CM (2019) Removal of polycyclic aromatic hydrocarbon (PAH)-contaminated sediments by persulfate oxidation and determination of degradation product cytotoxicity based on HepG2 and ZF4 cell lines. Environ Sci Pollut Res. https://doi.org/10.1007/s11356-019-04421-w

Gao Y, Qian H, Wang H, Chen J, Ren W, Yang F (2019) Assessment of background levels and pollution sources for arsenic and fluoride in the phreatic and confined groundwater of Xi'an city, Shaanxi. China Environ Sci Pollut Res. https://doi.org/10.1007/s11356-019-067917

Korekar G, Kumar A, Ugale C (2019) Occurrence, fate, persistence and remediation of caffeine: a review. Environ Sci Pollut Res. https:// doi.org/10.1007/s11356-019-06998-8

Le HQ, Nguyen TXQ, Chen S, Duong CC, Cao TN, Chang H, Ray SS, Nguyen NC (2019) Application of progressive freezing on forward osmosis draw solute recovery. Environ Sci Pollut Res. https://doi. org/10.1007/s11356-019-06079-w

Lee Y, Lin S (2019) Vulnerability and ecological footprint: a comparison between urban Taipei and rural Yunlin. Taiwan Environ Sci Pollut Res. https://doi.org/10.1007/s11356-019-05251-6

Li J, Zhu W, Dong H, Yang Z, Zhang P, Qiang Z (2019) Impact of carrier on ammonia and organics removal from zero-discharge marine recirculating aquaculture system with sequencing batch biofilm reactor (SBBR). Environ Sci Pollut Res. https://doi.org/10.1007/ s11356-019-04887-8

Miao S, Liu C, Qian B, Miao Q (2019) Remote sensing-based water quality assessment for urban rivers: a study in Linyi development area. Environ Sci Pollut Res. https://doi.org/10.1007/s11356-0184038-Z

Pang YL, Lim S, Lee RKL (2019) Enhancement of sonocatalytic degradation of organic dye by using titanium dioxide $\left(\mathrm{TiO}_{2}\right) /$ activated carbon (AC) derived from oil palm empty fruit bunch. Environ Sci Pollut Res. https://doi.org/10.1007/s11356-019-05373-x

Peng YP, Chang YC, Chen KF, Wang CH (2019) A field pilot-scale study on heavy metal-contaminated soil washing by using an environmentally friendly agent - poly- $\gamma$-glutamic acid ( $\gamma$-PGA). Environ Sci Pollut Res. https://doi.org/10.1007/s11356-01907444-5

Ren X, Zhang Y, Chen H (2019) Graywater treatment technologies and reuse of reclaimed water for toilet flushing. Environ Sci Pollut Res. https://doi.org/10.1007/s11356-019-05154-6

Sekine M, Wang J, Yamamoto K, Kanno A (2020) Fish habitat evaluation based on width-to-depth ratio and eco-environmental diversity index in small rivers. Environ Sci Pollut Res. https://doi.org/10. 1007/s11356-020-08691-7

Song Y, Song S (2019) Spiralling curve characterization of nitratenitrogen absorption in a channel at a rural-urban ecotone in
Northeast China. Environ Sci Pollut Res. https://doi.org/10.1007/ s11356-019-06354-w

Wang F, Yang F, Qi L (2020) Convergence of carbon intensity: a test on developed and developing countries. Environ Sci Pollut Res. https:// doi.org/10.1007/s11356-020-09175-4

Wanhong L, Fang L, Fan W, Maiqi D, Tiansen L (2019) Industrial water pollution and transboundary eco-compensation: analyzing the case of Songhua River Basin. China. Environ Sci Pollut Res. https://doi. org/10.1007/s11356-019-07254-9

Yeh G, Hoang HG, Lin C, Bui XT, Tran HT, Shern CC, Vu CT (2020) Assessment of heavy metal contamination and adverse biological effects of an industrially affected river. Environ Sci Pollut Res. https://doi.org/10.1007/s11356-020-07737-0

Zhou Z, Wang J, Su R, Guo Y, Zhao J, Zhang M, Ji R, Li Y, Li J (2019) Hydrogeochemical and isotopic characteristics of groundwater in Xinchang preselected site and their implications. Environ Sci Pollut Res. https://doi.org/10.1007/s11356-019-07208-1

Publisher's note Springer Nature remains neutral with regard to jurisdictional claims in published maps and institutional affiliations.

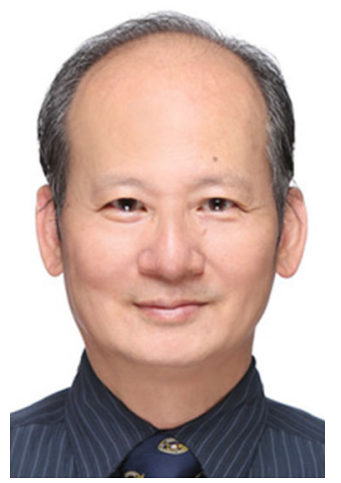

Dr. Chih-Huang Weng is a Full Professor in the Department of Civil and Ecological Engineering at I-Shou University, Kaohsiung, Taiwan. He received his MS and Ph.D. degrees in 1990 and 1994, respectively, from the Department of Civil Engineering of The University of Delaware, USA. He has published over 80 papers in SCI journals and 35 of them $\mathrm{H}-$ index with 4205 citations in Mendely database. He serves as the editor, editorial board member, and guest editor of several academic journals, such as Agricultural Water Management, Coloration Technology, Environmental Geochemistry and Health, and Environmental Science and Pollution Research. He has also organized and chaired several international conferences. His main research interests focus on using advanced oxidation processes and adsorption for the treatment of wastewater and bacteria inactivation, ground water modeling, and application of electrokinetic technologies to soil remediation/sludge treatment/activated carbon regeneration. 